\title{
Konektivitas Pelabuhan Dan Pembangunan Ekonomi Daerah Provinsi Maluku Utara
}

\author{
Abdurrahman Senuk ${ }^{1}$, Chairullah Amin'², Yetty ${ }^{3}$ \\ ${ }^{1,2,3}$ Dosen Jurusan Ekonomi Pembangunan, Universitas Khairun
}

Received: April 2019; Accepted: Agustus 2019; Published: September 2019

\begin{abstract}
Abstrak
Pendekatan pembangunan daerah yang berbasis pada kepulauan berbeda dengan pembangunan yang berbasis daratan. Keterbatasan alam yang dimiliki oleh wilayah kepulauan terkendala oleh beberapa karakteristik seperti terisolasi, kecil, terbatas, dan fragmentasi. Studi menganalisis dampak konektivitas pelabuhan terhadap pembangunan ekonomi daerah di provinsi kepulauan Maluku Utara. Metode analisis menggunakan model data panel terhadap 9 kabupaten/kota tahun 2010 - 2016 dengan indikator yang digunakan adalah GDP, panjang jalan, jumlah bongkar muat barang, tingkat kemampuan ekonomi, serta pelabuhan kontainer dan tol laut sebagai variabel dummy. Berdasarkan model common effect, hasil menunjukkan bahwa semua variabel independen memiliki pengaruh yang signifikan terhadap GDP kecuali jalan. Sementara berdasarkan Hausman test menujukkan bahwa model random efek lebih baik dari model fix effect dimana hasil pelabuhan kontainer dan tol laut tidak berdampak signifikan terhadap GDP. Hasil ini mengindikasikan bahwa kebijakan pengembangan tol laut tidak efektif untuk mengembangkan pembangunan ekonomi khususnya di wilayah yang berbasis pulau dan kepulauan
\end{abstract}

Kata kunci: konektivitas pelabuhan, ekonomi regional

\begin{abstract}
The local development approach based on islands is different with the developing of land area. The natural limitations possessed by the islands region that constrained by some characteristics such as isolation, smallness, boundless, and fragmentation. The study analyzes the impact of port connectivity to the local economic development by taking the case in the island province (North Maluku) in east Indonesia. The analysis method using the panel data model of 9 residences in period 2010-2016 in which the indicators that used are GDP, roadway, port throughput, economic density, and also container port, sea-tollway as the dummy variables. According to the common effect, model shows that all independent variables have a significant influence on the GDP except roadway. While based on Hausman test suggest that random effect model is more appropriated than FEM of which the result shows that container port and sea-tollway have not a significant impact on the GDP. These results implied that the policy of port connectivity within sea-tollway is not effective to improve the local economic development in particular in the islands based on region.
\end{abstract}

Keywords: port connectivity, regional economy

How to Cite: Senuk, A., Amin, C., Yetty (2019). Konektifitas Pelabuhan dan Pembangunan Ekonomi Daerah Provinsi Maluku Utara. JFRES: Journal of Fiscal and Regional Economy Studies, 2 (2), 34 - 41.

Corresponding author

E-mail: y.tarumadoja@gmail.com 


\section{PENDAHULUAN}

Pengembangan pelabuhan saat ini menjadi isu utama dalam mendorong daya saing perekonomian nasional dan daerah. Peran pelabuhan sangat mendukung perekonomian tingkat lokal dan nasional karena dapat mendorong pengembangan industri penyediaan lapangan kerja bagi penduduk lokal, serta menghasilkan pendapatan bagi pemerintah daerah. Pengaruh pelabuhan terhadap perekonomian lokal sudah pernah diteliti seperti Bottasso, Conti, Ferrari, \& Tei, (2014) melakukan penelitian terhadap 621 provinsi di Eropa. Dalam studinya membuktikan bahwa aktifitas pelabuhan berpengaruh terhadap peningkatan GDP di wilayah yang memiliki pelabuhan dan berdampak besar terhadap GDP di wilayah terdekatnya. Studi lain (Song \& van Geenhuizen, 2014) dengan melakukan panel data provinsi di China menemukan bahwa investasi infrastruktur pelabuhan berdampak positif terhadap pertumbuhan wilayah di Cina dengan tingkat perbedaan yang dimiliki oleh tiap-tiap wilayah berdasarkan pada perbedaan antara pelabuhan di laut dengan pelabuhan pedalaman, perbedaan kepadatan infrastruktur transportasi darat, tahapan pembangunan ekonomi dan kelebihan wilayah yang memiliki pelabuhan sendiri dibandingkan dengan wilayah tetanngganya yang tidak memiliki pelabuhan. Demikian pula Song \& van Geenhuizen (2014) menyatakan pengembangan efisiensi pelabuhan jauh lebih penting daripada pengembangan infrastruktur fisik semata, yaitu tata kelola manajemen pelabuhan yang lebih baik dan pengembangan konektivitas transportasi darat yang terintegrasi dengan rantai pasok yang terhubung dengan aktivitas ekonomi lokal.

Oleh karena itu disamping pembangunan infrastruktur pelabuhan untuk menekan biaya logistik, pengembangan konektivitas untuk wilayah Indonesia yang berbasis pulau dan kepulauan juga sangat penting untuk menunjang aksessabilitas ekonomi antar wilayah. Sebagai negara kepulauan dengan luas wilayah laut terluas serta memiliki garis pantai terpanjang kedua dunia, Indonesia memiliki jalur pelayaran strategis yang dapat dimamfaatkan sebagai basis pengembangan kekuatan geopolitik, ekonomi dan budaya bahari (Kusumastanto, 2012). Salah satu hasil penelitian menunjukkan bahwa peran konektivitas transportasi memiliki dampak terhadap aliran perdagangan di wilayah yang memiliki hubungan dagang daerah yang berdekatan dan secara sektoral mendapatkan mamfaat dari jaringan transportasi di wilayah tersebut (Alamá-Sabater, Márquez-Ramos, \& Suárez-Burguet, 2013). Studi lain yang dilakukan oleh Mohamed-Chérif \& Ducruet (2016) di kawasan Maghreb menunjukkan beberapa permasalahan logistik seperti tidak adanya rantai logistik yang terkodinir antar negara-negara maghreb menyebabkan biaya transportasi meningkat dikarenakan muatan kontainer yang kembali dalam keadaan kosong, sistem kordinasi yang tidak baik, dan biaya administrasi yang tidak murah. Disamping itu standar efisiensi rantai transportasi lebih rendah dari standar internasional disebabkan operasional pelabuhan yang tidak efisien seperti biaya pemeliharaan, prosedural pabean yang panjang, rendahnya partisipasi dari sektor swasta serta tingginya biaya transportasi antar wilayah di kawasan.

Pelabuhan dapat diartikan sebagai suatu tempat di wilayah pesisir pantai yang secara khusus berfungsi sebagai media pertukaran muatan antar kapal dan dapat dilihat sebagai simpul khusus untuk memudahkan konektivitas antar daerah yang saling berinteraksi (Kelly, 1998). Pelabuhan juga dapat di anggap sebagai tempat transhipment dimana rute pengiriman feeder terhubung satu sama lain dengan rute kargo melalui perjalanan laut (Rodrigue, 1997).

Karena fungsinya yang sangat strategis dalam perekonomian sehingga pelabuhan merupakan mesin pembangunan ekonomi wilayah melalui peningkatan ketersediaan lapangan kerja, pendapatan tenga kerja, pendapatan bisnis, dan penerimaan pajak bagi daerah. Mamfaat ini berkembang seiring dengan pembangunan dan operasional pelabuhan. Selama dalam proses pembangunan, kontraktor pengembang lokal dan tenaga kerja dipekerjakan dan bahan material pembangunan di daerah termamfaatkan secara ekonomi. Pekerjaan dalam operasional pelabuhan meliputi operator pelabuhan, perusahaan pengiriman barang baik melalui darat dan laut, dan penyedia layanan lainnya (agen kapal, perbaikan kapal, freight forwarder, jasa asuransi kelautan, akademi pelayaran, penyedia layanan pemandu dan penarik kapal. Manfaat lain dari pelabuhan 
secara tidak langsung yaitu ketika pendapatan dari upah tenaga kerja, keuntungan perusahaan, dan pajak yang diterima tersebut dibelanjakan seluruhnya atau sebagian di daerahnya. Pengeluaran yang dibelanjakan itu akan menghasilkan tambahan pendapatan bagi tenaga kerja, pengusaha, dan penerimaan pajak bagi daerah jika habis digunakan di retaurant, tempat hiburan, dan jasa profesional lainnya (Talley, 2009).

Paper ini bertujuan untuk menganalisis dampak pembangunan konektivitas pelabuhan terhadap pembangunan ekonomi daerah di wilayah kepulauan provinsi Maluku Utara. Pada bagian selanjutnya akan diuraikan metodologi penelitian, kemudian dilajutkan dengan hasil dan pembahasan. Dibagian akhir adalah kesimpulan dan implikasi kebijakan yang dapat berguna bagi pemangku kepentingan.

\section{METODE PENELITIAN}

Data panel yang di tetapkan dalam studi ini terdiri atas dua kategori yaitu karakteristik wilayah dan aktivitas pelabuhan. Untuk mengukur aktivitas pelabuhan menggunakan jumlah bongkar muat barang yang diperoleh dari 9 pelabuhan kargo di setiap kabupaten/kota provinsi Maluku Utara sementara untuk data ekonomi makro dikumpulkan dari kantor BPS kabupaten/kota seperti data luas wilayah, PDRB, jumlah penduduk, dan panjang jalan. Dikarenakan ketersediaan data yang cukup sedikit, periode waktu pengamatan dibatasi yaitu 2010-2016. Lokasi pelabuhan terletak di wilayah pulau dan pesisir di provinsi Maluku Utara sebagaimana terlihat pada Gambar 1 dan Tabel 1.

Dalam penelitian ini model regresi GDP dikembangkan untuk menghitung apakah aktivitas pelabuhan dalam bentuk konektivitas memiliki dampak positif terhadap ekonomi daerah. Untuk mengetahui kondisi pembangunan ekonomi digunakan variabel GDP/kapita sebagai variabel dependent sedangkan variabel independent meliputi indikator konektivitas pelabuhan dan faktor kontrol yang berkaitan dengan GDP. Konektivitas pelabuhan secara umum identik dengan aliran muatan barang pelabuhan yang diukur dengan ton untuk seluruh tipe jenis kargo (Shan, Yu, \& Lee, 2014). Studi lain juga menyatakan bahwa perhitungan aksesibilitas ekonomi berdasarkan pada kapasitas transportasi maksimum (TEUs/day) antar pelabuhan untuk mengukur aksesibilitas angkutan setiap elemen dalam jaringan pelayaran kapal (Tovar, Hernández, \& Rodríguez-Déniz, 2015). Dalam penelitian ini jumlah muatan barang hanya menggunakan jumlah bongkat muat barang kargo dan kontainer yang diangkut oleh kapal berdasarkan pada standar perhitungan BPS Indonesia. Satu set variabel kontrol digunakan untuk menggambarkan faktor-faktor selain konektivitas pelabuhan. Variabel-variabel tersebut diperoleh dari kantor statistik daerah yang berkaitan dengan GDP seperti panjang jalan raya dan tingkat kemampuan ekonomi.

Selanjutnya model regresi digunakan untuk menghitung hubungan antara ekonomi wilayah dan konektivitas pelabuhan dengan mengembangkan model regresi linear data panel dalam bentuk sebagai berikut:

$G D P=\beta 0+\beta 1$ ln Throughput $_{i t}+\beta 2$ ln jalan $_{i t}$ $+\beta 3 \quad$ ln econ_density ${ }_{i t}+\mu_{i t}$

Dimana GDP adalah pendapatan perkapita, $1 n$ throughput $_{\text {it }}$ adalah aktivitas pelabuhan yaitu jumlah muatan bongkar muat pelabuhan di wilayah $i$ pada waktu $t$, sedangkan ln roadway dan ln econ_density merupakan variabel kontrol dan $\mu_{\mathrm{it}}=e \mathrm{i}+\mathrm{t}_{\mathrm{t}}+\mathrm{v}_{\mathrm{it}}$ adalah error term, dimana $e \mathrm{i}$ adalah satu set wilayah unobserved fixed effects, $\mathrm{t}_{\mathrm{t}}$ adalah komponen waktu yang menggambarkan temporel fixed effects, dan $\mathrm{v}_{\mathrm{it}}$ adalah idiosyncratic error term. Semua variabel independent diukur dalam bentuk natural logs untuk memperoleh dampak relatif GDP dan menghilangkan efek skala. Spesifikasi model yang sama juga pernah digunakan dalam literatur yang lain (Shan et al., 2014 dan Bottasso et al., 2013). Dummy pertama $\left(D_{1}\right)$ adalah pelabuhan kontainer yaitu pelabuhan yang menangani aktivitas kapal kontainer dengan nilai 1 jika $\mathrm{x}_{1}>0$; dummy kedua $\left(D_{2}\right)$ yaitu tol laut yaitu wilayah yang dilalui oleh kapal tol laut dengan nilai 1 if $x_{2}>$ 0 dimana kedua variabel dummy ini menyatakan apakah pengembangan konektivitas pelabuhan dalam wilayah memiliki dampak positif atau negatif terhadap ekonomi daerah.

$$
\begin{aligned}
& G D P=\beta 0+\beta 1 \text { ln } \text { Throughput }_{i t}+\beta 2 \text { ln jalan }_{i t} \\
& +\beta 3 \text { ln econ_density }{ }_{i t}+\beta 4 \text { kontainer } \\
& +\beta 5-\text { tollaut }+\mu_{i t}
\end{aligned}
$$




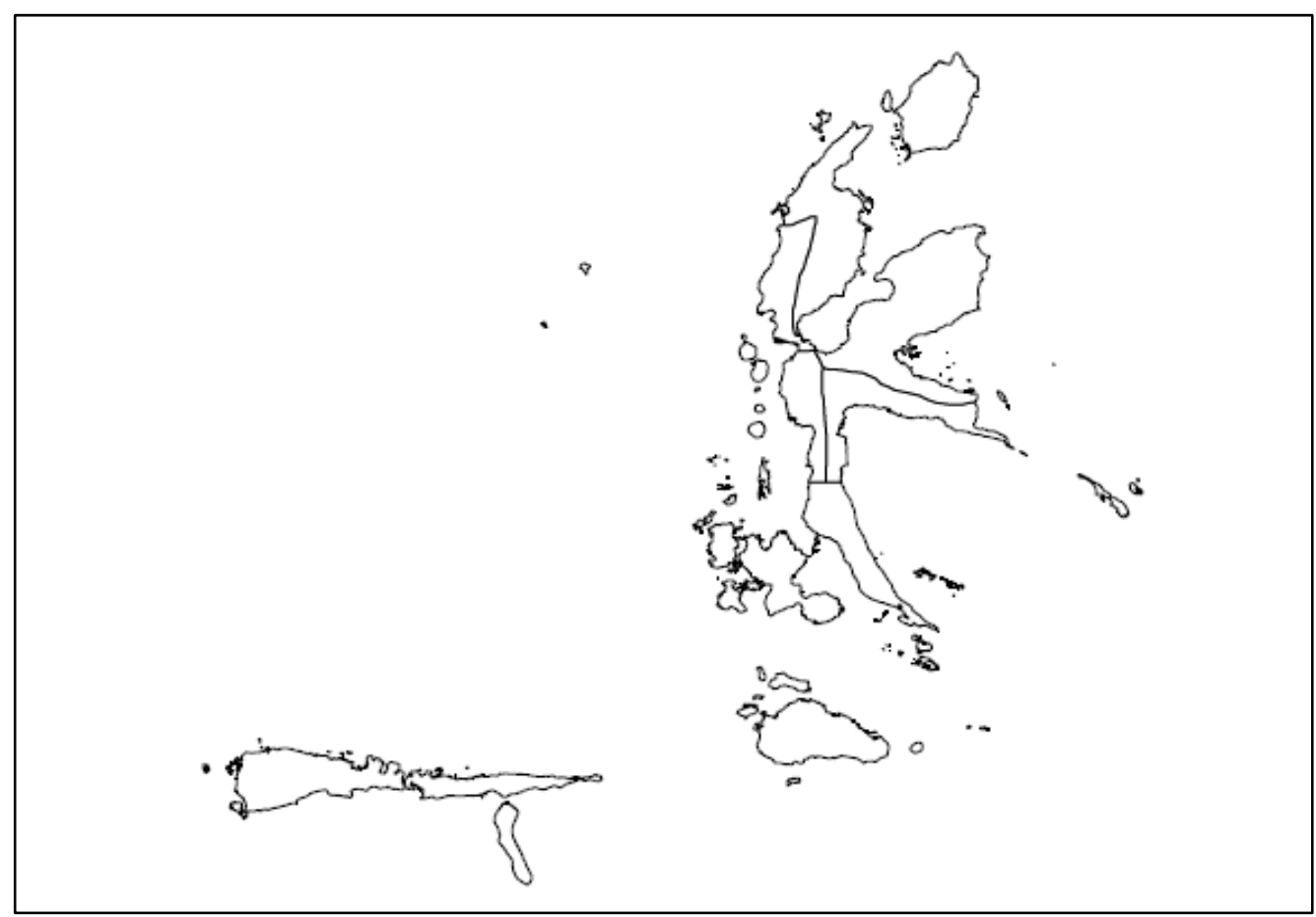

Gambar 1. Peta Lokasi Penelitian

Tabel 1. Informasi Umum Kabupaten/Kota Provinsi Maluku Utara

\begin{tabular}{|c|c|c|c|c|c|c|c|c|}
\hline \multirow[b]{2}{*}{ No } & \multirow[b]{2}{*}{ Kabupaten/Kota } & \multicolumn{5}{|c|}{ Average (2010 -2016) } & \multirow[b]{2}{*}{$\begin{array}{l}\text { Pelabuhan } \\
\text { Kontainer }\end{array}$} & \multirow[b]{2}{*}{$\begin{array}{l}\text { Toll } \\
\text { Laut }\end{array}$} \\
\hline & & $\begin{array}{c}\text { GDP/Capita } \\
\text { Juta (Rp) }\end{array}$ & $\begin{array}{l}\text { Throughput } \\
\text { (Ton) }\end{array}$ & $\begin{array}{r}\text { Jalan } \\
(\mathrm{Km}) \\
\end{array}$ & $\begin{array}{l}\text { Penduduk } \\
\text { (Jiwa) }\end{array}$ & $\begin{array}{l}\text { Area } \\
\left(\mathrm{Km}^{2}\right)\end{array}$ & & \\
\hline 1 & Ternate & 22,90 & 460.633 & 314,66 & 201.212 & 250,85 & $\mathrm{Y}$ & $\mathrm{Y}$ \\
\hline 2 & Tidore & 15,13 & 36.162 & 405,24 & 94.334 & 9564,2 & $\mathrm{~N}$ & $\mathrm{Y}$ \\
\hline 3 & Halmahera Selatan & 12,93 & 2.003 .218 & 1210,77 & 211.466 & 8779,32 & $\mathrm{~N}$ & $\mathrm{Y}$ \\
\hline 4 & Halmahera Barat & 10,52 & 24.908 & 735,76 & 106.485 & 2612,24 & $\mathrm{~N}$ & $\mathrm{~N}$ \\
\hline 5 & Halmahera Tengah & 22,97 & 116.224 & 445,31 & 46.880 & 2276,83 & $\mathrm{~N}$ & $\mathrm{~N}$ \\
\hline 6 & Halmahera Timur & 21,65 & 501.418 & 796,36 & 80.310 & 6506,2 & $\mathrm{~N}$ & $\mathrm{~N}$ \\
\hline 7 & Halmahera Utara & 16,30 & 173.769 & 610,26 & 174.364 & 5447,3 & $\mathrm{~N}$ & $\mathrm{Y}$ \\
\hline 8 & Morotai & 12,17 & 47.652 & 50,14 & 60.751 & 2476 & $\mathrm{~N}$ & $\mathrm{Y}$ \\
\hline 9 & Kep. Sula & 11,71 & 48.368 & 584,18 & 289.354 & 9632,92 & $\mathrm{~N}$ & $\mathrm{~N}$ \\
\hline & Rata-Rata Wilayah & 16,25 & 379.150 & 573 & 140.573 & 5282,87 & & \\
\hline
\end{tabular}

Sumber: BPS Provinsi Maluku Utara diolah.

Tabel 2. Rangkuman Statistik

\begin{tabular}{llrrrr}
\hline Variabel & Unit & Minimum & Maximum & Mean & S.D \\
\hline GDP/Kapita & Juta (Rp) & 11.968 & 26.543 & 16.427 & 5.122 \\
Throughput & Cargo (Ton) & 8.236 & 15.449 & 11.635 & 1.439 \\
Jalan & Kilometres & 3.555 & 7.430 & 6.092 & 0.885 \\
Econ_Density & GDP/Area & 4.809 & 10.046 & 6.141 & 1.381 \\
\hline
\end{tabular}

\section{Sumber: data diolah}




\section{HASIL DAN PEMBAHASAN}

Sebelum menghitung persamaan (1) dan (2), pertama-tama dilakukan uji unit root untuk mengukur data yang digunakan dalam model regresi untuk mengetahui tingkat akurasi hasil regresi. Untuk menguji unit root, kami menggunakan metode yang diperkenalkan oleh Harris dan Tzavalis (1999) yang secara khusus digunakan untuk data panel dengan jumlah series yang pendek. Hasil uji unit root menunjukkan bahwa koefisien autokorelasi $\rho$ dari test Harris-Tzavails untuk GDP/kapita sebesar $-0,3153 \quad(p$-value $=0,000), \quad \operatorname{lnThrp}$ $0,2444 \quad(p$-value $=0,0011)$ dimana semua variabel secara nyata signifikan pada tingkat kepercayaan 5\%. Sehingga hasil secara tegas menolak hipotesis nol bahwa semua panel mengandung unit root sebagaimana ditunjukkan pada Tabel 3 .

Tabel 3. Uji Unit root Variabel Dependen dan Independen

\begin{tabular}{lrrrr}
\hline & GDP/kpta & LnThrp & Lnjalan & LnEcon_den \\
\hline$\rho$ & $-0,3153$ & 0,2444 & 0,3953 & $-0,0864$ \\
$p$-value & 0,0000 & 0,0011 & 0,0321 & 0,0458 \\
\hline
\end{tabular}

Hasil estimasi pada masing-masing wilayah tanpa variabel dummy (model I) seperti yang ditunjukkan pada tabel 4 menunjukkan bahwa hanya variabel kepadatan ekonomi (econ_den) yang memiliki pengaruh positif terhadap PDB per kapita, sebaliknya variabel jumlah throughput dan jalan tidak signifikan pada level $5 \%$. Sedangkan dengan memasukkan variabel dummy port (model II) menunjukkan bahwa semua variabel tidak berpengaruh signifikan terhadap PDB perkapita kecuali variabel kepadatan ekonomi (econ_den).

Hasil model menunjukkan bahwa pengembangan konektivitas pelabuhan melalui pengembangan jalur kapal Tol-Laut di wilayah kepulauan provinsi Maluku Utara belum efektif mempengaruhi peningkatan PDB daerah kabupaten yang dilalui.
Ada berbagai masalah yang ditemukan dalam menerapkan kebijakan tol-laut di provinsi Maluku Utara. Pertama, biaya pengangkutan barang yang lebih murah dan lebih aman karena sudah menggunakan kontainer dimamfaatkan oleh oknum pedagang lokal untuk mengambil keuntungan dengan memberlakukan harga yang sama untuk komoditas bahan kebutuhan pangan. Padahal biaya angkut kontainer dengan menggunakan kapal tol-laut jauh lebih murah sehingga seharusnya harga kebutuhan yang dipasok dapat menurun. Namun faktanya hal tersebut tidak terjadi, harga untuk jenis komoditas seperti beras dan minyak goreng tetap sama dengan sebelum kapal tol-laut masuk.

Tabel 4. Hasil Regressi: model tanpa dummi

\begin{tabular}{rrrrr}
\hline & ln Throughput & \multicolumn{1}{c}{ ln Jalan } & ln Econ_den & Adj R \\
\hline Model I & 0.167 & 1.664 & $2.844^{* * *}$ & 0,2729 \\
& $(0.374)$ & $(1.381)$ & $(0.337)$ & \\
\hline
\end{tabular}

Keterangan : Standar erros parentheses

** Statistical significance pada $5 \%$ level

*** Statistical significance pada $1 \%$ level

Tabel 5. Hasil Regressi: model dengan dummi

\begin{tabular}{ccccccc}
\hline & ln Throughput & $\ln$ Jalan & $\ln$ Econ_den & $D 1$ (Kontainer) & $D 2$ (Tol Laut) & Adj R \\
\hline \multirow{2}{*}{ Model II } & 0.098 & 0.703 & $5.298^{* *}$ & -14.548 & 1.185 & 0,2358 \\
& $(0.374)$ & $(1.534)$ & $(2.370)$ & $(11.445)$ & $(1.183)$ & \\
\hline
\end{tabular}

Keterangan: Standar erros in parentheses

** Statistical significance pada $5 \%$ level

*** Statistical significance pada $1 \%$ level 
Tabel 6. Hasil Regresi Lima Pelabuhan Wilayah Yang Dilalui Oleh Kapal Tol Laut

\begin{tabular}{|c|c|c|c|c|c|}
\hline Pelabuhan & lnThrougput & lnJalan & lnEconomicDensity & Tol Laut & Adj R \\
\hline \multirow[t]{2}{*}{ Ternate } & -1.115 & -0.206 & $14.859 * * *$ & 0.396 & 0,9946 \\
\hline & $(0.436)$ & $(0.490)$ & $(0.740)$ & $(0.249)$ & \\
\hline \multirow[t]{2}{*}{ Tidore } & 0.373 & -0.615 & $11.233 * * *$ & -0.108 & 0,999 \\
\hline & $(0.135)$ & $(0.246)$ & $(0.310)$ & $(0.110)$ & \\
\hline \multirow{2}{*}{ Halmahera Selatan } & 0.016 & 0.065 & $8.394 * * *$ & 0.081 & 0,9993 \\
\hline & $(0.006)$ & $(0.110)$ & $(0.206)$ & $(0.041)$ & \\
\hline \multirow[t]{2}{*}{ Halmahera Utara } & 6.326 & -14.360 & 6.333 & -0.300 & 0,8962 \\
\hline & (7.134) & $(16.801)$ & $(5.557)$ & $(0.787)$ & \\
\hline \multirow[t]{2}{*}{ Morotai } & -31.443 & -14.837 & 120.582 & -0.310 & 0,3647 \\
\hline & $(14.379)$ & $(7.976)$ & $(55.242)$ & $(2.164)$ & \\
\hline
\end{tabular}

Keterangan : Standar erros in parentheses

*** Statistical significance at $1 \%$ level

Selain itu tingkat kecukupan muatan kapal pada perjalanan pulang sering kosong sehingga mempengaruhi waktu tunggu kapal berlabuh di pelabuhan, akibatnya jadwal keberangkatan kapal menjadi tidak pasti dan lama. Oleh karena itu ketidakpastian jadwal keberangkatan dan lamanya waktu perjalanan ke pelabuhan tujuan yang lebih panjang daripada menggunakan kapal kontainer pribadi. Dalam kasus Maluku Utara di tahun 2016 waktu perjalanan dari pelabuhan Ternate ke Makassar di Sulawesi Selatan membutuhkan perjalanan selama 23 hari dibandingkan jika menggunakan kapal kargo swasta yang hanya memiliki 7 hingga 9 hari diangkut langsung dari Ternate ke pelabuhan tujuan seperti Tanjung Perak di Surabaya, Jawa Timur. Di sisi lain desain kapal laut tol yang tidak dilengkapi dengan kontainer sesuai dengan komoditas unggulan lokal di wilayah timur Indonesia seperti reefer container untuk perikanan.

Oleh karena itu kebijakan tol laut sebagai strategi untuk menekan biaya logistik yang tinggi di Indonesia timur terkendala dengan dukungan sarana infrastruktur pelabuhan lokal dan kemampuan prduktivitas daerah yang rendah dalam mengoptimalkan potensi sumberdaya alam yang dimiliki. Sebagaimana yang pernah diungkap oleh Maqbul (2018) bahwa pengawasan yang minim dari aparat pemerintah terhadap para pengusaha ekspedisi serta keterlibatan oknum aparata dalam melakukan manipulasi data manifest jumlah muatan masih terjadi sehingga diperlukan kerjasama dan sinergitas antar lembaga terkait dalam pengawasan dan pelaksanaan program tol laut. Disamping itu pengembangan efisiensi pelabuhan jauh lebih penting daripada sekedar pengembangan infrastruktur fisik semata seperti tata kelola manajemen pelabuhan yang lebih baik dan pengembangan konektivitas transportasi darat yang terintegrasi dengan rantai pasok yang terhubung dengan aktivitas ekonomi lokal.

Pengembangan konektivitas pelabuhan di wilayah yang berbasis pulau-pulau kecil dan kepulauan harus memperhatikan karakteristik alamiah wilayah yang dimilikinya seperti kerentanan dalam skala ekonomi yang kecil dalam kegiatan produksi dan penyediaan jasa, ketidakmampuan ekonomi pulau dalam menjangkau dan mempengaruhi pasar, serta keterisolasian dari pusat pembangunannya. Kerr (2005) menguraikan beberapa hambatan yang berkaitan dengan isu pembangunan pulau-pulau kecil yaitu keterbatasan sumberdaya alam dan sumberdaya manusia, infrastruktur tidak ekonomis, keterbatasan dalam penyediaan layanan dan administrasi, biaya transportasi yang tinggi, sistem transportasi laut dan darat yang buruk dan rentan terhadap dampak bencana alam.

Dikarenakan keterbatasannya dalam skala ekonomi yang cenderung kecil maka pengembangan konektivitas di pulau-pulau harus mampu menciptakan suatu proses transformasi sosial dan ekonomi sehingga menurut Kusumastanto (2003) masyarakat di pulau-pulau harus dapat diberdayakan secara ekonomi, sosial, dan budaya dan kebijakan pengembangan pulau-pulau harus ditekankan pada kekuatan sumberdaya lokal yang bertujuan untuk mengurangi biaya transportasi, menghasilkan proses diversifikasi produk yang tinggi sehingga terjadi transaksi perdagangan dengan keragaman produk dengan daerah lain. 


\section{KESIMPULAN}

Pembangunan konektivitas pelabuhan di daerah yang berbasis pulau dan kepulauan masih terkendala oleh fasilitas infrastruktur pelabuhan yang masih minim dan buruknya sistem moda transportasi laut dan darat. Oleh karena itu untuk dapat meningkatkan dampak ekonomi lokal dari aktivitas pengembangan konektivitas pelabuhan maka yang paling penting dilakukan yaitu kebijakan yang diarahkan untuk pengembangan efisiensi pelabuhan seperti tata kelola manajemen pelabuhan yang lebih baik, konektivitas transportasi darat dan laut disertai dengan integrasi yang kuat dari pelabuhan dengan sistem rantai pasok yang terhubung dengan ekonomi regional.

Untuk wilayah pulau-pulau hal yang dapat dilakukan adalah suatu kebijakan yang dapat menstimulus terciptanya spesialisasi komoditas unggulan daerah, bernilai tambah tinggi, pembangunan sistem pelabuhan berkluster sesuai dengan karakteristik aktivitas ekonomi serta pelayanan para stakeholder maritim yang lebih baik. Untuk itu pembangunan keterkaitan antar pelabuhan dengan sistem kluster komoditas/wilayah sehingga nilai tambah produk atau komoditas dapat meningkat. Dalam hal ini penyediaan kapal tol laut yang dilengkapi dengan fasilitas reefer container yang khusus untuk komoditas perikanan sangat cocok dikembangkan di wilayah Indonesia Timur. Selain itu hal yang paling penting lainnya adalah pembangunan konektivitas antar moda pengangkutan darat dan laut untuk memperbaiki jaringan sistem transportasi disamping dengan melakukan investasi pada fasilitas pelabuhan.

\section{DAFTAR PUSTAKA}

Alamá-Sabater, L., Márquez-Ramos, L., \& Suárez-Burguet, C. (2013). Trade and transport connectivity: A spatial approach. Applied Economics, 45(18), 2563-2566. https://doi.org/10.1080/00036846.2012.669 466

Bottasso, A., Conti, M., Ferrari, C., Merk, O., \& Tei, A. (2013). The impact of port throughput on local employment: Evidence from a panel of European regions. Transport Policy, 27, 32-38. https:// doi.org/10.1016/j.tranpol.2012.12.001

Bottasso, A., Conti, M., Ferrari, C., \& Tei, A. (2014). Ports and regional development: A spatial analysis on a panel of European regions. Transportation Research Part A, 65, 44-55. https://doi.org/10.1016/ j.tra. 2014.04.006

Calatayud, A., Mangan, J., \& Palacin, R. (2017). Connectivity to international markets: A multi-layered network approach. Journal of Transport Geography, 61(June 2016), 6171. https://doi.org/10.1016/j.jtrangeo.2017. 04.006

Clark, X., Dollar, D., \& Micco, A. (2004). Port efficiency, maritime transport costs, and bilateral trade. Journal of Development Economics, 75(2 SPEC. ISS.), 417-450. https://doi.org/10.1016/j.jdeveco.2004.06.0 05

Deng, P., Lu, S., \& Xiao, H. (2013). Evaluation of the relevance measure between ports and regional economy using structural equation modeling. Transport Policy, 27, 123-133. https://doi.org/10.1016/j.tranpol.2013.01.0 08

Fahmiasari, H., \& Parikesit, D. (2017). Container Shipping Network Efficiency Comparison in Indonesia: Nusantara Pendulum and Sea Tollway. Asian Journal of Shipping and Logistics, 33(2), 79-84. https://doi.org/10.1016/j.ajsl.2017.06.005

Harris, R. D. F., \& Tzavalis, E. (1999). Inference for unit roots in dynamic panels where the time dimension is fixed. Journal of Econometrics, 91(2), 201-226. https://doi.org/10.1016/S03044076(98)00076-1

Kelly, M. E. O. (1998). A geographer's analysis of hub-and- spoke networks '. Location Science.

Kerr, S. A. (2005). What is small island sustainable development about? Ocean and Coastal Management, 48(7-8), 503-524. https://doi.org/10.1016/j.ocecoaman.2005.0 3.010

Kusumastanto, T. (2012). Ekonomi Kelautan. Pusat Kajian Sumberdaya dan Pesisir Laut. Universitas IPB. Bogor.

Mappangara, A. C. (2015). Sea Transportation Network Order of Sulawesi Corridor for Supporting Connectivity of Region, 4(11), 744-751.

Mohamed-Chérif, F., \& Ducruet, C. (2016). Regional integration and maritime 
connectivity across the Maghreb seaport system. Journal of Transport Geography, 51, 280-293. https://doi.org/10.1016 /j.jtrangeo.2015.01.013

Park, J. S., \& Seo, Y. J. (2016). The impact of seaports on the regional economies in South Korea: Panel evidence from the augmented Solow model. Transportation Research Part E: Logistics and Transportation Review, 85, 107-119. https://doi.org/10.1016/j.tre.2015.11.009

Raga, P., Yamin Jinca, M., Pallu, S., Sitepu, G., \& Eng, M. (2014). Container Transport Network Analysis of Investment Region and Port Transhipment for Sulawesi Economic Corridor. International Refereed Journal of Engineering and Science (IRJES) ISSN (Online), 3(4), 2319-183. Retrieved from www.irjes.org

Rodrigue, J. . claude comtois. (1997). Transportation and spatial cycles : evidence from maritime system. Journal of Transport Geography, 5, 87-98.

Shan, J., Yu, M., \& Lee, C. Y. (2014). An empirical investigation of the seaport's economic impact: Evidence from major ports in China. Transportation Research Part E: Logistics and Transportation Review, 69, 41-53. https://doi.org/ 10.1016/j.tre.2014.05.010

Song, L., \& van Geenhuizen, M. (2014). Port infrastructure investment and regional economic growth in China: Panel evidence in port regions and provinces. Transport Policy, 36, 173-183. https://doi.org/ 10.1016/j.tranpol.2014.08.003

Tovar, B., Hernández, R., \& Rodríguez-Déniz, H. (2015). Container port competitiveness and connectivity: The Canary Islands main ports case. Transport Policy, 38, 40-51. https://doi.org/10.1016/j.tranpol.2014.11.0 01

Zaman, M. B., Vanany, I., \& Awaluddin, K. D. (2015). Connectivity Analysis of Port in Eastern Indonesia. Procedia Earth and Planetary Science, 14, 118-127. https:// doi.org/10.1016/j.proeps.2015.07.092 